\title{
HIGH-PERFORMANCE THIN-LAYER CHROMATOGRAPHY FINGERPRINT PROFILE OF BAUHINIA TOMENTOSA LINN. LEAVES
}

\author{
BALABHASKAR R ${ }^{1}$, VIJAYALAKSHMI $\mathbf{K}^{2 *}$ \\ ${ }^{1}$ Department of Biochemistry, Research Scholar, Bharathiar University, Coimbatore, Tamil Nadu, India. ${ }^{2}$ Department of Biochemistry, \\ Bharathi Women's College, Chennai, Tamil Nadu, India. Email: viji42research@yahoo.co.in
}

Received: 24 October 2017, Revised and Accepted: 21 November 2017

\section{ABSTRACT}

Objective: Chromatographic fingerprint is an effective method for doing the fingerprinting of a plant species. In this study, high-performance thinlayer chromatography (HPTLC) analysis of Bauhinia tomentosa was done in n-hexane, chloroform, and ethanol extracts.

Methods: The extract of leaves was developed using toluene:ethyl acetate:formic acid:glacial acetic acid (7:3:0.1:0.1) for n-hexane, toluene:ethyl acetate:formic acid (6:2:0.5) for chloroform, and chloroform:methanol:formic acid (8:1.5:0.2) for ethanol extract as mobile phase using standard procedures and scanned under ultraviolet at $254 \mathrm{~nm}, 366 \mathrm{~nm}$, and $520 \mathrm{~nm}$.

Results: The HPTLC fingerprinting results showed several peaks with different $\mathrm{R}_{\mathrm{f}}$ values. The HPTLC fingerprinting of $\mathrm{n}$-hexane extract at $266 \mathrm{~nm}$ showed 15 peaks. The HPTLC fingerprinting of chloroform extract at $520 \mathrm{~nm}$ showed 22 peaks. The HPTLC fingerprinting of the ethanol extract at $366 \mathrm{~nm}$ showed 13 peaks.

Conclusion: These fingerprinting results will be helpful in the identification and authentication of the species and also to identify new bioactive components in this medicinal plant.

Keywords: High-performance thin-layer chromatography, Bauhinia tomentosa, Ethanol extract, Chromatography, Fingerprinting, Medicinal plants.

(c) 2018 The Authors. Published by Innovare Academic Sciences Pvt Ltd. This is an open access article under the CC BY license (http://creativecommons. org/licenses/by/4. 0/) DOI: http://dx.doi.org/10.22159/ajpcr.2018.v11i2.23294

\section{INTRODUCTION}

Indian traditional medicine is one of the richest medicinal systems available around the world. The phytochemicals identified from traditional medicinal plants are providing an excellent opportunity for the development of new types of therapeutics [1]. This plantbased traditional medicine system continues to play an essential role in health care [2]. The revival of significant and the emergent market of herbal medicine products necessitate strong commitment by stakeholders to safeguard the end users. Furthermore, various hazardous side effects, hypersensitivity reactions, effects from adulterants, and interactions with herbal drugs have been confirmed, drawing the consideration of many regulatory agencies for the standardization of plant-based drugs [3]. The World Health Organization has developed specific guiding principles to support the associated countries to instigate nationalized policies on plantbased drugs and to study their prospective safety, efficacy, and quality, as a prerequisite for global harmonization [4-6]. Standardization of the plant material is need of the day. Several pharmacopeia containing monographs of the plant materials describe only the physicochemical characters. Hence, the modern methods describing the identification and quantification of active constituents in the plant material may be useful for proper standardization of herbs and its formulations $[7,8]$.

Technological advancements which take place in the processes of isolation, purification, and structural elucidation of natural compounds have made it possible to generate different strategies for the analysis and standardization of plant-based medicines [4]. A variety of sophisticated methods such as spectrophotometric, chromatographic, polarography, electrophoresis, and the use of biomarkers in fingerprints are presently employed in the standardization procedures. Thin-layer chromatography (TLC) and high-performance TLC (HPTLC) fingerprint profiles are used for ensuring the identity, transparency, and potency of herbal formulations [9].

HPTLC fingerprint is mostly used for evaluating the compounds with low or moderate polarities [10]. The advantage of HPTLC is that several samples can be run simultaneously using a same quantity of mobile phase, thus lowering analysis time and cost per analysis, and it has an added advantage in that the resolution of chemically similar compounds is better than the conventional TLC and low amount of sample is required [11]. HPTLC can serve as a tool for identification, authentication, and quality of herbal drug [12].

Bauhinia tomentosa commonly known as yellow bell orchid tree belongs to Fabaceae family is one of the best, versatile, and most commonly used household remedies for many manifestations. The generic name commemorates the Bauhin brothers Jean and Gaspard, the Swiss botanists; the two lobes of the leaf exemplify the two brothers. Tomentosa derived from tomentose, meaning with dense, interwoven hairs. It is commonly known as "Kanchini" in Tamil and "Phalgu" in Sanskrit [13].

In this study, fingerprinting of $B$. tomentosa leaves was done by successive extraction using hexane, chloroform, and ethanol solvents with the appropriate mobile phases.

\section{METHODS}

Instrumentation

A Camag HPTLC system (Muttenz, Switzerland) equipped with a sample applicator LinomatV, twin trough plate development chamber, TLC scanner 3, win CATS software, and Hamilton (Reno, Nevada, USA) Syringe $(100 \mu \mathrm{L})$ was used. 
Material and reagents

HPLC grade ethanol, ethyl acetate, hexane, acetic acid, and formic acid were obtained from E. Merck, India).

\section{Sample collection}

The leaves of $B$. tomentosa Linn. were collected from Villivakkam, Chennai, and authenticated by Dr. S. Jayaraman, Director of Plant and Anatomy Research Centre, West Tambaram, Chennai (Authentication No. PARC/2014/2294).

\section{Sample preparation}

$2 \mathrm{~g}$ of the sample was loaded in Millipore cellulose thimble and extracted with $100 \mathrm{ml}$ of n-hexane exhaustively in a Soxhlet distillation apparatus. After that, the extract was concentrated in a water bath by distillation process and was transferred into a beaker using minimum quantity of hexane and dried over a water bath to free hexane. This extract was dissolved in hexane and made up to $10 \mathrm{ml}$ in a standard flask. The process was again continued with chloroform and then with ethanol.

\section{Chromatographic conditions}

Stationary phase: Silica gel $\mathrm{GF}_{254}$

Mobile phase

i. For n-hexane extract: Toluene: EA:FA: GAA (7:3:0.1:0.1)

ii. For chloroform extract: Toluene: EA:FA (6:2:0.5)

iii. For ethanol extract: Chloroform:methanol: FA (8:1.5:0.2)

Scanning wavelength: $254 \mathrm{~nm}, 366 \mathrm{~nm}$, and $520 \mathrm{~nm}$

Sample concentration: Extract (50 mg/ml)

Applied volume: Track $1(10 \mu \mathrm{l})$, track $2(15 \mu \mathrm{l})$, and track $3(20 \mu \mathrm{l})$,

Development mode: Ascending mode.

Then, the plate was scanned using Camag's Scanner 4 at $\lambda 254 \mathrm{~nm}$ (D2 lamp, absorption mode) and $\lambda 366 \mathrm{~nm}$ (Hg lamp, fluorescence mode), respectively, and fingerprint profiles of the extract were detected. Subsequently, the plate was dipped in 5\% sulfuric acid in alcohol followed by heating at $105^{\circ} \mathrm{C}$ till the development of the coloration of the spots. The plate was then photo documented in white light using Camag's TLC visualizer and scanned at $\lambda 520 \mathrm{~nm}$ (W light, Absorption mode).

\section{RESULTS}

The HPTLC fingerprinting of $n$-hexane extract of Bauhinia tomentosa was shown in Fig. 1. The chromatograms shown in Fig. 1a indicate that all sample constituents were clearly separated without any diffusion and tailing. Table 1 shows the Rf values of various bands in chromatogram (track 3). It is observed from Table 1a that, in $20 \mu \mathrm{L}$ (track 3) of n-hexane extract of $B$. tomentosa leaves (at $254 \mathrm{~nm}$ ), there are 15 spots with $R_{f}$ values of $0.01,0.08,0.15,0.17,0.20,0.25,0.30$, $0.40,0355,0.61,0.67,0.71,0.77,0.86$, and 0.95 . Of the 15 components in $20 \mu \mathrm{L}$ of hexane extract, the compounds with $\mathrm{R}_{\mathrm{f}}$ value 0.67 and 0.01 were found to be more predominant as the percentage area was more with $25.78 \%$ and $12.32 \%$, respectively. The remaining components were found to be very less in quantity as the percent area of all the spots was $<10 \%$.

It is observed from Table $1 \mathrm{~b}$ that, in $20 \mu \mathrm{L}$ of $\mathrm{n}$-hexane extract of $B$. tomentosa leaves, there are 11 spots (at $366 \mathrm{~nm}$ ) with $\mathrm{R}_{\mathrm{f}}$ values of $0.01,0.08,0.26,0.45,0.63,0.66,0.69,0.76,0.80,0.90$, and 0.98 . Of the 11 components in $20 \mu \mathrm{L}$ of hexane extract, the compounds with $\mathrm{R}_{\mathrm{f}}$ value $0.63,0.66,0.76$, and 0.80 were found to be more predominant as the percentage area was $47.25 \%, 14.96 \%, 11.13 \%$, and $10.07 \%$, respectively. The remaining components were found to be very less in quantity as the percent area of all the spots were $<10 \%$. The chromatograms shown in Fig. 1b indicate that all the constituents were clearly separated without diffusion and tailing.
Table 1: $R_{\mathrm{f}}$ values of various bands in chromatogram (track-3)

\begin{tabular}{|c|c|c|c|c|c|}
\hline \multicolumn{2}{|c|}{$\lambda=254 \mathrm{~nm}$} & \multicolumn{2}{|c|}{$\lambda=366 \mathrm{~nm}$} & \multicolumn{2}{|c|}{$\begin{array}{l}\lambda=520 \mathrm{~nm} \\
\text { (derivatized) }\end{array}$} \\
\hline Color & $\begin{array}{l}R_{f} \\
\text { value (s) }\end{array}$ & Color & $\begin{array}{l}R_{f} \\
\text { value (s) }\end{array}$ & Color & $\begin{array}{l}R_{\mathrm{f}} \\
\text { value (s) }\end{array}$ \\
\hline Green & 0.06 & Red & 0.26 & Dark & 0.17 \\
\hline Green & 0.16 & Red & 0.36 & Dark & 0.21 \\
\hline Green & 0.20 & Red & 0.40 & Pink & 0.26 \\
\hline Green & 0.39 & Red & 0.45 & Dark & 0.40 \\
\hline Green & 0.60 & Red & 0.55 & Violet & 0.49 \\
\hline Green & 0.65 & Red & 0.59 & Green & 0.66 \\
\hline Green & 0.68 & Red & 0.65 & Maroon & 0.69 \\
\hline \multirow[t]{2}{*}{ Green } & 0.77 & Red & 0.70 & Maroon & 0.72 \\
\hline & & & & Dark & 0.78 \\
\hline
\end{tabular}

Table 1a: $R_{\mathrm{f}}$ values of various bands in chromatogram (track 3 ) at $254 \mathrm{~nm}$

\begin{tabular}{llll}
\hline Peak & Max $\mathbf{R}_{\mathrm{f}}$ & Max height & Area \% \\
\hline 1 & 0.01 & 181.6 & 12.32 \\
2 & 0.08 & 56.3 & 3.82 \\
3 & 0.15 & 40.0 & 2.72 \\
4 & 0.17 & 59.3 & 4.03 \\
5 & 0.20 & 108.7 & 7.37 \\
6 & 0.25 & 59.0 & 4.01 \\
7 & 0.30 & 29.4 & 2.00 \\
8 & 0.40 & 29.5 & 2.00 \\
9 & 0.55 & 10.7 & 0.73 \\
10 & 0.61 & 88.1 & 5.98 \\
11 & 0.67 & 379.9 & 25.78 \\
12 & 0.71 & 86.9 & 5.90 \\
13 & 0.77 & 142.8 & 9.69 \\
14 & 0.86 & 56.5 & 3.84 \\
15 & 0.95 & 144.7 & 9.82 \\
\hline
\end{tabular}

Table $1 \mathrm{~b}$ : $\mathbf{R}_{\mathrm{f}}$ values of various bands in chromatogram (track 3 ) at $366 \mathrm{~nm}$

\begin{tabular}{llll}
\hline Peak & Max $\mathbf{R}_{\mathbf{f}}$ & Max height & Area \% \\
\hline 1 & 0.01 & 40.4 & 2.31 \\
2 & 0.08 & 21.4 & 1.22 \\
3 & 0.26 & 11.2 & 0.64 \\
4 & 0.45 & 26.5 & 1.51 \\
5 & 0.63 & 827.4 & 47.25 \\
6 & 0.66 & 262.0 & 14.96 \\
7 & 0.69 & 42.9 & 2.45 \\
8 & 0.76 & 194.9 & 11.13 \\
9 & 0.80 & 176.3 & 10.07 \\
10 & 0.90 & 14.2 & 0.81 \\
11 & 0.98 & 133.9 & 7.65 \\
\hline
\end{tabular}

Table 1c: $R_{f}$ values of various bands in chromatogram (track 3 ) at $520 \mathrm{~nm}$ (derivatized)

\begin{tabular}{llll}
\hline Peak & Max $_{\mathrm{f}}$ & Max height & Area \% \\
\hline 1 & 0.01 & 119.6 & 6.86 \\
2 & 0.09 & 56.8 & 3.26 \\
3 & 0.17 & 35.4 & 2.03 \\
4 & 0.21 & 70.8 & 4.06 \\
5 & 0.26 & 29.9 & 1.72 \\
6 & 0.40 & 67.1 & 3.85 \\
7 & 0.49 & 252.4 & 14.48 \\
8 & 0.57 & 134.4 & 7.71 \\
9 & 0.69 & 326.1 & 18.70 \\
10 & 0.73 & 225.0 & 12.91 \\
11 & 0.78 & 303.7 & 17.42 \\
12 & 0.89 & 122.3 & 7.01 \\
\hline
\end{tabular}


The chromatogram shown in Fig. 1c indicates that all sample constituents were clearly separated without any diffusion and tailing. It is observed from Table 1c that, in $20 \mu \mathrm{L}$ (track 3) of n- hexane extract of $B$. tomentosa leaves, there are 12 spots with $\mathrm{R}_{\mathrm{f}}$ values of $0.01,0.09,0.17,0.21,0.26,0.40,0.49,0.57,0.69,0.73,0.78$, and 0.89 . Of the 12 components in $20 \mu \mathrm{L}$ of n-hexane extract, the compounds with $R_{f}$ value of $0.69,0.78,0.49$, and 0.73 were found to be more predominant as the percentage area was more with $18.70 \%, 17.42 \%$, $14.48 \%$, and $12.91 \%$, respectively. The remaining components were found to be very less in quantity as the percent area of all the spots was $<10 \%$.

Fig. 2 shows the HPTLC fingerprinting of chloroform extract of Bauhinia tomentosa. The chromatogram shown in Fig. 2a indicates

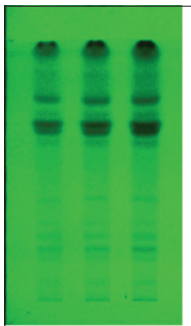

$254 \mathrm{~nm}$

Track $1-10 \mu \mathrm{L}$

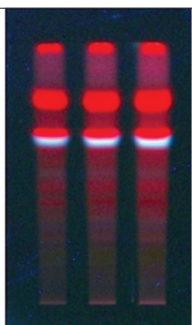

$366 \mathrm{~nm}$

Track $2-15 \mu \mathrm{L}$

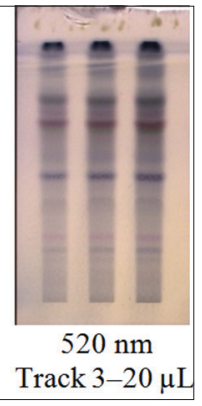

Track 3-20 $\mu \mathrm{L}$
Fig. 1: High-performance thin-layer chromatography fingerprinting of hexane extract of Bauhinia tomentosa

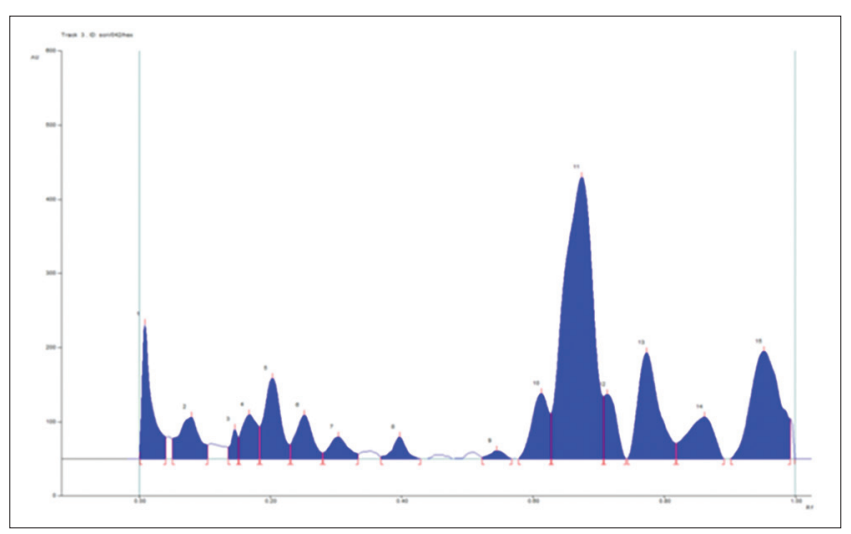

Fig. 1a: High-performance thin-layer chromatography (track 3) at $254 \mathrm{~nm}$

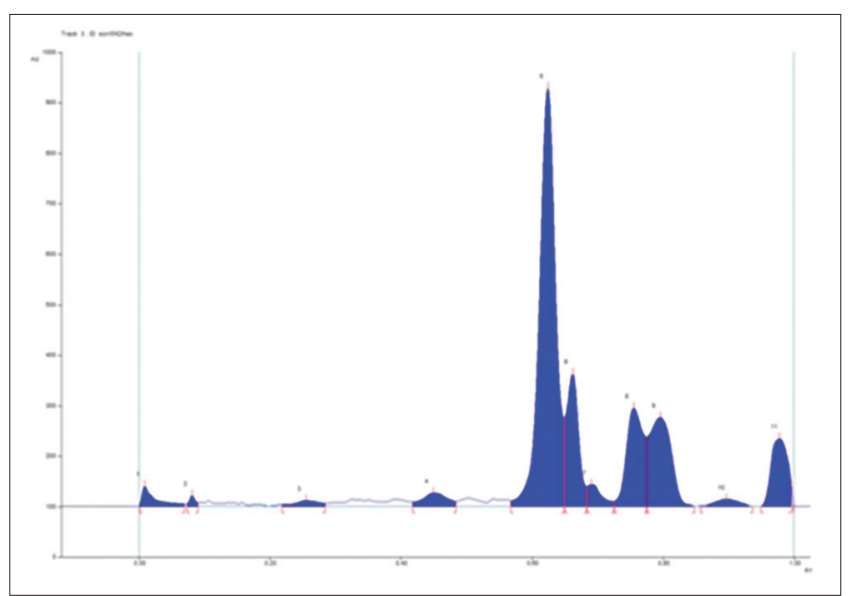

Fig. 1b: High-performance thin-layer chromatography of n-hexane extract (track 3) at $366 \mathrm{~nm}$ that all sample constituents were clearly separated into distinct bands without any diffusion and tailing. The Rf values of various bands in chromatogram (track 2) was depicted in Table 2. It is observed from Table 2a that, at $254 \mathrm{~nm}, 15 \mu \mathrm{L}$ (track 2) of chloroform extract of B. tomentosa leaves was separated into 11 bands with $\mathrm{R}_{\mathrm{f}}$ values of $0.00,0.10,0.20,0.30,0.35,0.42,0.51,0.56,0.65,0.75$, and 0.94 , respectively. Of the 11 components in $15 \mu \mathrm{L}$ of chloroform extract, the compounds with $\mathrm{Rf}$ value $0.75,0.00$, and 0.42 were found to be more predominant as the percentage area was more with $29.76 \%$, $14.91 \%$, and $12.34 \%$, respectively. The remaining components were found to be very less in quantity as the percent area of all the spots was $<10 \%$.

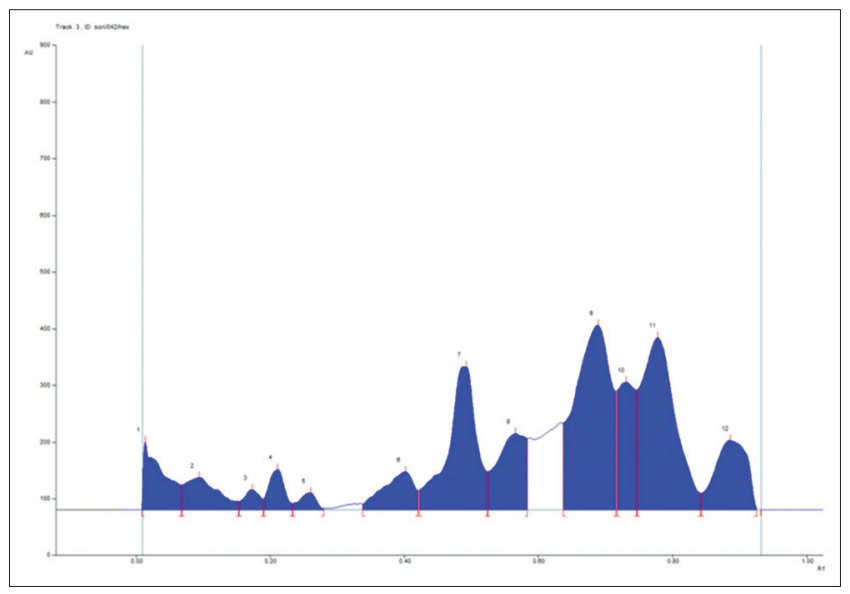

Fig. 1c: High-performance thin-layer chromatography of n-hexane extract (track 3) at $520 \mathrm{~nm}$ (derivatized)

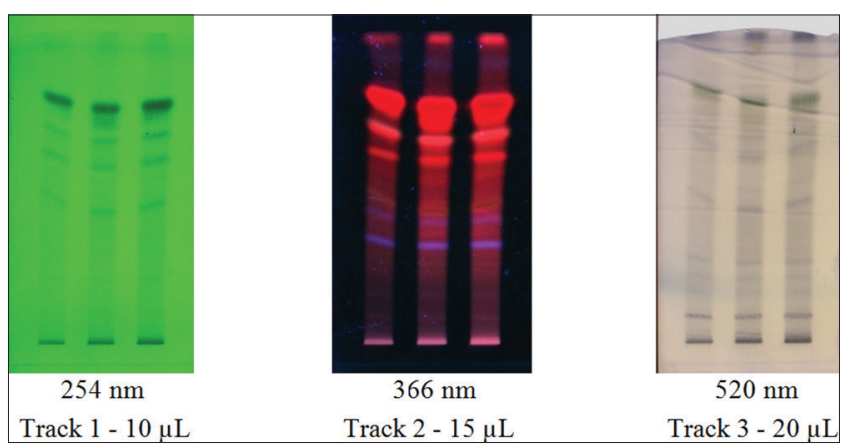

Fig. 2: High-performance thin-layer chromatography fingerprinting of chloroform extract of Bauhinia tomentosa

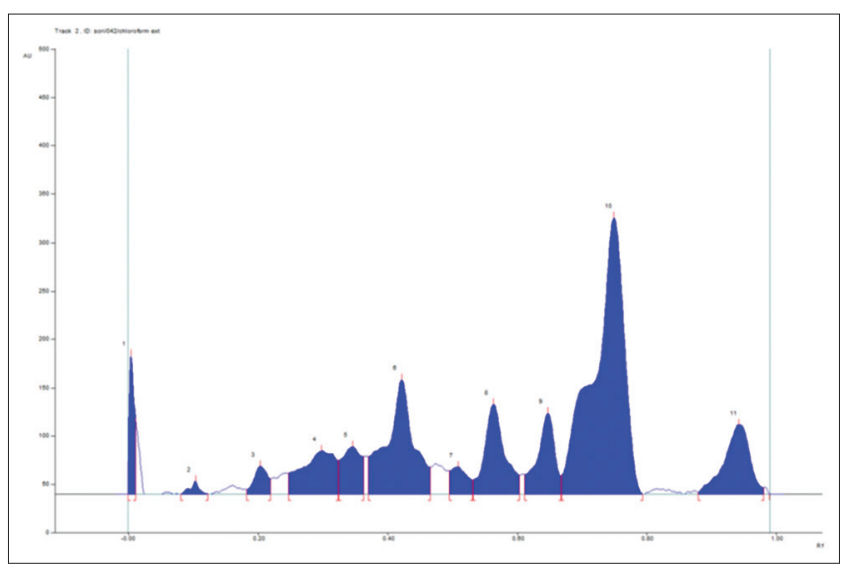

Fig. 2a: High-performance thin-layer chromatography (track 2) at $254 \mathrm{~nm}$ 
It is observed from Table $2 \mathrm{~b}$ that, in $15 \mu \mathrm{L}$ (track 2 at $366 \mathrm{~nm}$ ) of chloroform extract of $B$. tomentosa leaves, there are 21 spots with $\mathrm{R}_{\mathrm{f}}$ values of $0.00,0.09,0.16,0.23,0.26,0.31,0.35,0.39,0.41,0.43,0.52$, $0.59,0.65,0.70,0.73,0.77,0.83,0.86,0.89,0.90$, and 0.97 values. Of the 21 components in $15 \mu \mathrm{L}$ of chloroform extract, the compounds with $R_{f}$ values 0.65 and 0.77 were found to be more predominant as the percentage area was more with $14.93 \%$ and $13.89 \%$, respectively. The remaining components were found to be very less in quantity as the percent area of all the spots was $<10 \%$. The chromatogram shown in Fig. $2 \mathrm{~b}$ indicates that all the constituents were clearly separated without any diffusion and tailing.

The chromatogram shown in Fig. 2c indicates that all the sample constituents were clearly separated into distinct bands without any

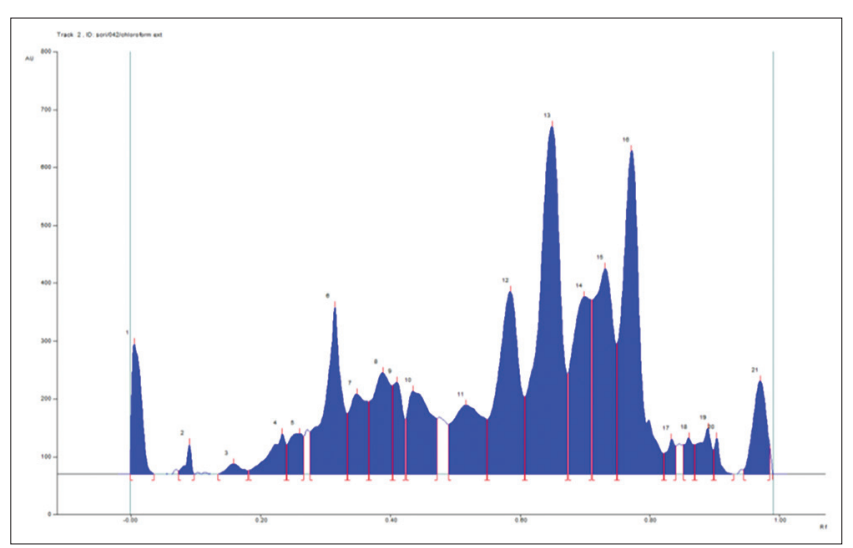

Fig. 2b: High-performance thin-layer chromatography (track 2) at $366 \mathrm{~nm}$

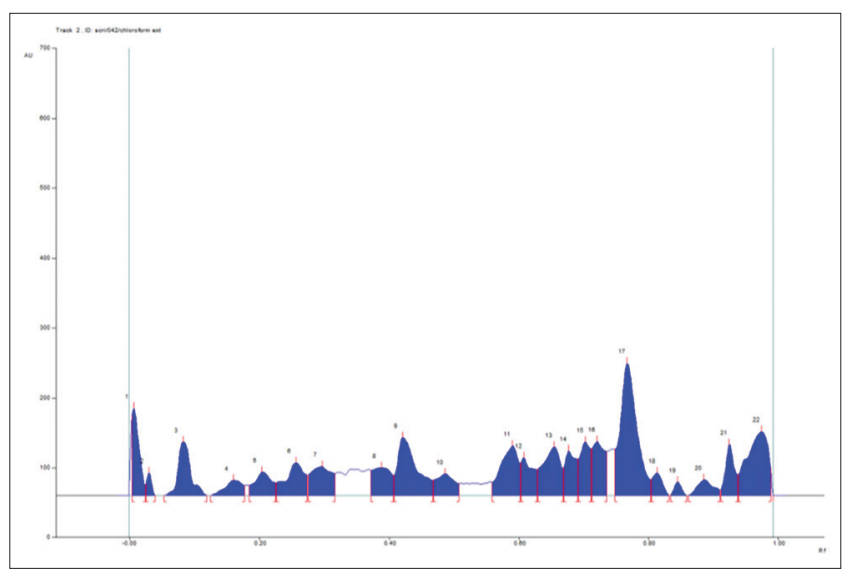

Fig. 2c: High-performance thin-layer chromatography (derivatized; track 2) at $520 \mathrm{~nm}$

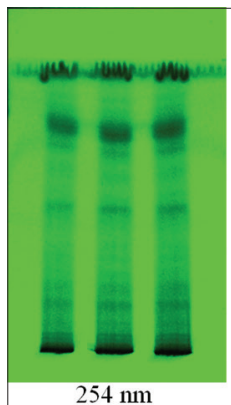

Track $1-10 \mu \mathrm{L}$

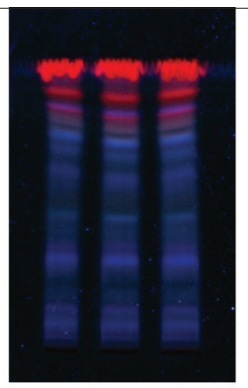

$366 \mathrm{~nm}$ Track $2-15 \mu \mathrm{I}$

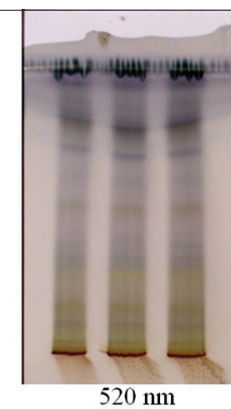

Track 3-20 $\mu \mathrm{L}$
Fig. 3: High-performance thin-layer chromatography fingerprinting of ethanol extract of $B$. tomentosa diffusion and tailing. It is observed from Table $2 \mathrm{c}$ that, in $15 \mu \mathrm{L}$ of chloroform extract of $B$. tomentosa leaves (track 2 at $520 \mathrm{~nm}$ ), there are 22 spots with $\mathrm{R}_{\mathrm{f}}$ values of $0.01,0.03,0.08,0.16,0.20,0.26,0.30,0.39$, $0.42,0.49,0.59,0.61,0.65,0.68,0.70,0.72,0.77,0.81,0.84,0.89,0.92$, and 0.97 . Of the 22 components in $15 \mu \mathrm{L}$ of chloroform extract, the compounds with $\mathrm{R}_{\mathrm{f}}$ value 0.77 was found to be more predominant as the percentage area was more with $13.84 \%$, respectively. The remaining components were found to be very less in quantity as the percent area of all the spots was $<10 \%$.

The HPTLC fingerprinting of ethanol extract of Bauhinia tomentosa was illustrated in Fig. 3. The chromatogram shown in Fig. 3a indicates that

Table 2: Rf values of various bands in chromatogram (track 2)

\begin{tabular}{|c|c|c|c|c|c|}
\hline \multicolumn{2}{|c|}{$\lambda=254 \mathrm{~nm}$} & \multicolumn{2}{|c|}{$\lambda=366 \mathrm{~nm}$} & \multicolumn{2}{|c|}{$\begin{array}{l}\lambda=520 \\
\mathrm{~nm} \text { (derivatized) }\end{array}$} \\
\hline Color & $\begin{array}{l}R_{\mathrm{f}} \\
\text { value (s) }\end{array}$ & Color & $\begin{array}{l}R_{\mathrm{f}} \\
\text { value (s) }\end{array}$ & Color & $\begin{array}{l}R_{\mathrm{f}} \\
\text { value (s) }\end{array}$ \\
\hline Green & 0.20 & Red & 0.09 & Dark & 0.09 \\
\hline Green & 0.35 & Red & 0.17 & Dark & 0.21 \\
\hline Green & 0.43 & Violet & 0.33 & Dark & 0.26 \\
\hline Green & 0.57 & Red & 0.40 & Dark & 0.43 \\
\hline Green & 0.66 & Red & 0.53 & Dark & 0.60 \\
\hline \multirow[t]{2}{*}{ Green } & 0.77 & Red & 0.66 & Dark & 0.67 \\
\hline & & & & Green & 0.78 \\
\hline
\end{tabular}

Table 2a: $\mathbf{R}_{\mathrm{f}}$ values of various bands in chromatogram (track 2) at $254 \mathrm{~nm}$

\begin{tabular}{llll}
\hline Peak & Max $\mathbf{R}_{\mathrm{f}}$ & Max height & Area \% \\
\hline 1 & 0.00 & 143.3 & 14.91 \\
2 & 0.10 & 13.6 & 1.42 \\
3 & 0.20 & 28.8 & 3.00 \\
4 & 0.30 & 44.7 & 4.65 \\
5 & 0.35 & 49.1 & 5.11 \\
6 & 0.42 & 118.6 & 12.34 \\
7 & 0.51 & 28.3 & 2.95 \\
8 & 0.56 & 93.0 & 9.68 \\
9 & 0.65 & 83.7 & 8.71 \\
10 & 0.75 & 285.9 & 29.76 \\
11 & 0.94 & 71.9 & 7.48 \\
\hline
\end{tabular}

Table $2 \mathbf{b}$ : $\mathbf{R}_{\mathrm{f}}$ values of various bands in chromatogram (track 2) at $366 \mathrm{~nm}$

\begin{tabular}{llll}
\hline Peak & Max $\mathbf{R}_{\mathbf{f}}$ & Max height & Area \% \\
\hline 1 & 0.00 & 225.6 & 5.60 \\
2 & 0.09 & 52.3 & 1.30 \\
3 & 0.16 & 17.8 & 0.44 \\
4 & 0.23 & 69.9 & 1.74 \\
5 & 0.26 & 69.9 & 1.74 \\
6 & 0.31 & 289.3 & 7.19 \\
7 & 0.35 & 138.5 & 3.44 \\
8 & 0.39 & 175.3 & 4.36 \\
9 & 0.41 & 159.1 & 3.95 \\
10 & 0.43 & 143.2 & 3.56 \\
11 & 0.52 & 118.9 & 2.95 \\
12 & 0.59 & 316.2 & 7.86 \\
13 & 0.65 & 601.1 & 14.93 \\
14 & 0.70 & 306.9 & 7.62 \\
15 & 0.73 & 355.9 & 8.84 \\
16 & 0.77 & 559.2 & 13.89 \\
17 & 0.83 & 60.9 & 1.51 \\
18 & 0.86 & 62.7 & 1.56 \\
19 & 0.89 & 78.7 & 1.96 \\
20 & 0.90 & 62.4 & 1.55 \\
21 & 0.97 & 161.5 & 4.01 \\
\hline
\end{tabular}


all the sample constituents were clearly separated without any diffusion and tailing. The Rf values of various bands in track 3 of chromatogram was depicted in Table 3. It is observed from Table 3a that, in $20 \mu \mathrm{L}$ of ethanol extract of $B$. tomentosa leaves (track 3 at $254 \mathrm{~nm}$ ), there are 13 spots with $\mathrm{R}_{\mathrm{f}}$ values $0.04,0.10,0.16,0.22,0.27,0.32,0.35,0.49,0.61$, $0.69,0.75,0.86$, and 0.94 . Of the 13 components in $20 \mu \mathrm{L}$ of ethanol extract, the compounds with $\mathrm{R}_{\mathrm{f}}$ value $0.94,0.69$, and 0.75 were found to be more predominant as the percentage area was more with $28.51 \%$, $26.37 \%$, and $11.11 \%$, respectively. The remaining components were

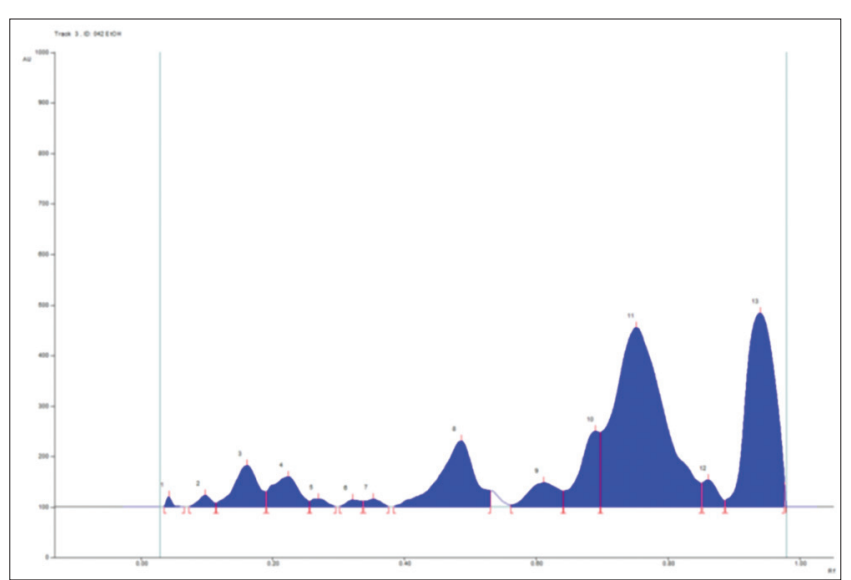

Fig. 3a: High-performance thin-layer chromatography (track 3) at $254 \mathrm{~nm}$

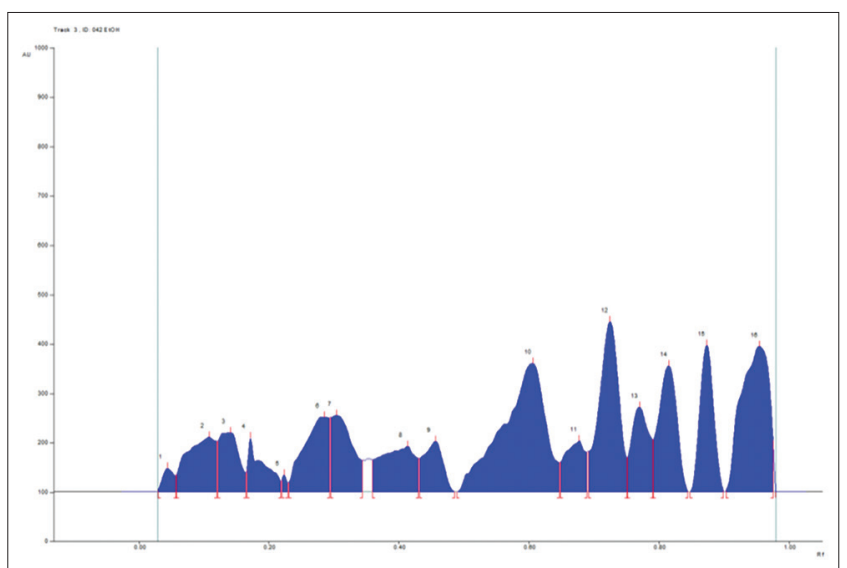

Fig. 3b: High-performance thin-layer chromatography (track 3) at $366 \mathrm{~nm}$

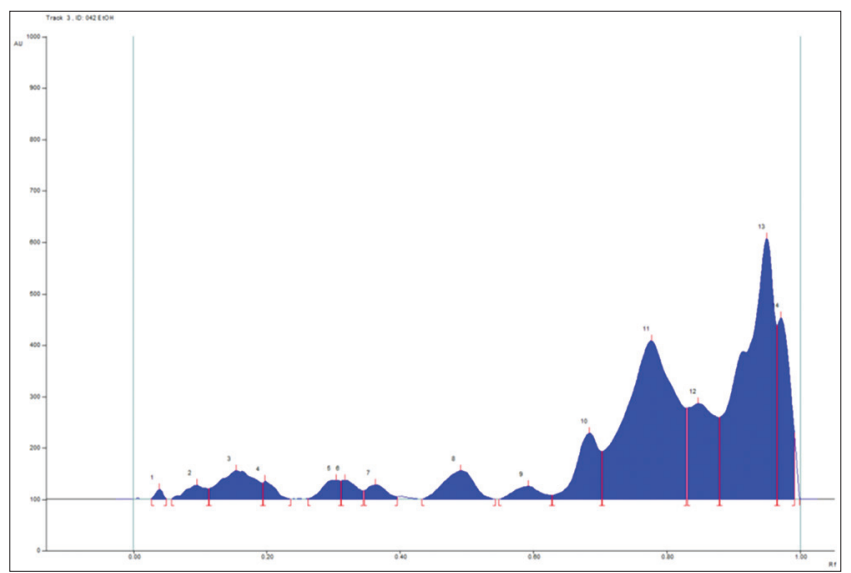

Fig. 3c: High-performance thin-layer chromatography (track 3; derivatized) at $520 \mathrm{~nm}$ found to be very less in quantity as the percent area of all the spots was $<10 \%$.

It is observed from Table $3 \mathrm{~b}$ that, in $20 \mu \mathrm{L}$ of ethanol extract of $B$. tomentosa leaves (track 3 at $366 \mathrm{~nm}$ ), there are 16 spots with $\mathrm{R}_{\mathrm{f}}$ values $0.04,0.11,0.14,0.17,0.22,0.29,0.30,0.41,0.46,0.61,0.68,0.73$, $0.77,0.82,0.87$, and 0.96 , respectively. Of the 16 components in $20 \mu \mathrm{L}$ of

Table 2c: $R_{\mathrm{f}}$ values of various bands in chromatogram (track 2) at $520 \mathrm{~nm}$

\begin{tabular}{llll}
\hline Peak & Max $\mathbf{R}_{\mathrm{f}}$ & Max height & Area \% \\
\hline 1 & 0.01 & 124.8 & 9.13 \\
2 & 0.03 & 32.3 & 2.37 \\
3 & 0.08 & 76.7 & 5.61 \\
4 & 0.16 & 21.6 & 1.58 \\
5 & 0.20 & 33.6 & 2.46 \\
6 & 0.26 & 46.6 & 3.41 \\
7 & 0.30 & 41.3 & 3.02 \\
8 & 0.39 & 39.6 & 2.90 \\
9 & 0.42 & 82.7 & 6.05 \\
10 & 0.49 & 30.9 & 2.26 \\
11 & 0.59 & 70.8 & 5.18 \\
12 & 0.61 & 53.5 & 3.92 \\
13 & 0.65 & 69.4 & 5.08 \\
14 & 0.68 & 63.4 & 4.64 \\
15 & 0.70 & 76.4 & 5.59 \\
16 & 0.72 & 76.8 & 5.62 \\
17 & 0.77 & 189.1 & 13.84 \\
18 & 0.81 & 31.9 & 2.34 \\
19 & 0.84 & 19.0 & 1.39 \\
20 & 0.89 & 22.1 & 1.62 \\
21 & 0.92 & 73.0 & 5.34 \\
22 & 0.97 & 91.2 & 6.67 \\
\hline
\end{tabular}

Table 3: $\mathbf{R}_{\mathrm{f}}$ values of various bands in chromatogram (track)

\begin{tabular}{|c|c|c|c|c|c|}
\hline \multicolumn{2}{|c|}{$\lambda=254 \mathrm{~nm}$} & \multicolumn{2}{|l|}{$\lambda=366 \mathrm{~nm}$} & \multicolumn{2}{|c|}{$\begin{array}{l}\lambda=520 \mathrm{~nm} \\
\text { (derivatized) }\end{array}$} \\
\hline Color & $\begin{array}{l}R_{f} \\
\text { value (s) }\end{array}$ & Color & $\begin{array}{l}R_{f} \\
\text { value (s) }\end{array}$ & Color & $\begin{array}{l}R_{f} \\
\text { value (s) }\end{array}$ \\
\hline Green & 0.07 & Indigo & 0.14 & Dark & 0.05 \\
\hline Green & 0.17 & Indigo & 0.32 & Violet & 0.10 \\
\hline Green & 0.33 & $\begin{array}{l}\text { Fluorescent } \\
\text { blue }\end{array}$ & 0.46 & Yellow & 0.17 \\
\hline Green & 0.50 & Indigo & 0.60 & Yellow & 0.28 \\
\hline Green & 0.61 & Indigo & 0.67 & Violet & 0.38 \\
\hline Green & 0.68 & Indigo & 0.72 & Brown & 0.49 \\
\hline Green & 0.87 & Red & 0.80 & Violet & 0.60 \\
\hline & & Red & 0.88 & Violet & 0.68 \\
\hline
\end{tabular}

Table 3a: $\mathbf{R}_{\mathrm{f}}$ values of various bands in chromatogram (track 3 ) at $254 \mathrm{~nm}$

\begin{tabular}{llll}
\hline Peak & Max $_{\mathbf{f}}$ & Max height & Area \% \\
\hline 1 & 0.04 & 19.8 & 1.47 \\
2 & 0.10 & 22.7 & 1.69 \\
3 & 0.16 & 81.4 & 6.05 \\
4 & 0.22 & 59.5 & 4.42 \\
5 & 0.27 & 15.2 & 1.13 \\
6 & 0.32 & 13.6 & 1.01 \\
7 & 0.35 & 14.9 & 1.11 \\
8 & 0.49 & 130.1 & 9.68 \\
9 & 0.61 & 47.4 & 3.53 \\
10 & 0.69 & 149.4 & 11.11 \\
11 & 0.75 & 354.6 & 26.37 \\
12 & 0.86 & 5.6 & 3.91 \\
13 & 0.94 & 383.4 & 28.51 \\
\hline
\end{tabular}


Table $3 b$ : $\mathbf{R}_{\mathrm{f}}$ values of various bands in chromatogram (track 3 ) at $366 \mathrm{~nm}$

\begin{tabular}{llll}
\hline Peak & Max $_{\mathbf{f}}$ & Max height & Area \% \\
\hline 1 & 0.04 & 47.4 & 1.79 \\
2 & 0.11 & 110.4 & 4.17 \\
3 & 0.14 & 119.7 & 4.53 \\
4 & 0.17 & 109.3 & 4.13 \\
5 & 0.22 & 34.2 & 1.29 \\
6 & 0.29 & 151.0 & 5.71 \\
7 & 0.30 & 154.5 & 5.84 \\
8 & 0.41 & 91.9 & 3.47 \\
9 & 0.46 & 101.9 & 3.85 \\
10 & 0.61 & 259.8 & 9.82 \\
11 & 0.68 & 103.4 & 3.91 \\
12 & 0.73 & 344.3 & 13.02 \\
13 & 0.77 & 171.5 & 6.48 \\
14 & 0.82 & 254.8 & 9.63 \\
15 & 0.87 & 297.0 & 11.23 \\
16 & 0.96 & 294.5 & 11.13 \\
\hline
\end{tabular}

Table 3c: $R_{\mathrm{f}}$ values of various bands in chromatogram (track 3; derivatized) at $520 \mathrm{~nm}$

\begin{tabular}{llll}
\hline Peak & Max $\mathbf{R}_{\mathbf{f}}$ & Max height & Area \% \\
\hline 1 & 0.04 & 18.8 & 1.05 \\
2 & 0.09 & 27.1 & 1.51 \\
3 & 0.15 & 55.3 & 3.07 \\
4 & 0.20 & 64.6 & 1.92 \\
5 & 0.30 & 37.0 & 2.06 \\
6 & 0.32 & 36.8 & 2.04 \\
7 & 0.36 & 27.7 & 1.54 \\
8 & 0.49 & 55.4 & 3.08 \\
9 & 0.59 & 24.6 & 1.37 \\
10 & 0.68 & 128.0 & 7.12 \\
11 & 0.78 & 307.7 & 17.12 \\
12 & 0.85 & 185.6 & 10.32 \\
13 & 0.95 & 506.9 & 28.20 \\
14 & 0.97 & 352.4 & 19.60 \\
\hline
\end{tabular}

ethanol extract, the compounds with $\mathrm{R}_{\mathrm{f}}$ value $0.73,0.87$, and 0.96 were found to be more predominant as the percentage area was more with $13.02 \%, 11.23 \%$, and $11.13 \%$, respectively. The remaining components were found to be very less in quantity as the percent area of all the spots was $<10 \%$. The chromatograms shown in Fig. $3 \mathrm{~b}$ indicate that all the sample constituents were clearly separated into distinct bands without any diffusion and tailing.

The chromatograms shown in Fig. 3c indicate that all the sample constituents were clearly separated without any diffusion and tailing. It is observed from Table $3 \mathrm{c}$ that, in $20 \mu \mathrm{L}$ of ethanol extract of $B$. tomentosa leaves (track 3 at $520 \mathrm{~nm}$ ), there are 14 spots with Rf values 0.04, 0.09, $0.15,0.20,0.30,0.32,0.36,0.49,0.59,0.68,0.78,0.85,0.95$, and 0.97, respectively. Of the 14 components in $20 \mu \mathrm{L}$ of ethanol extract, the compounds with Rf value $0.95,0.97,0.78$, and 0.85 were found to be more predominant as the percentage area was more with $28.20 \%, 19.60 \%$, $17.12 \%$, and $10.32 \%$, respectively. The remaining components were found to be very less in quantity as the percent area of all the spots was $<10 \%$.

\section{DISCUSSION}

HPTLC fingerprinting is a valuable tool for the analysis of phytochemicals because of sensitivity and cost-effectively. The fingerprinting of a plant will help in the identification and quality control of a particular species. It can also give information that will be useful for the isolation, purification, characterization, and identification of marker compounds of the species. In the present study, the developed chromatograms will be specific with the selected solvent systems for the hexane, chloroform, and ethanol extracts, respectively. The presence of many spots in every chromatogram indicates the presence of different phytochemicals in varying concentrations in the plant. Devaki et al. have reported the presence of phenols, flavonoids, tannin, and cardiac glycosides in B. tomentosa using HPTLC technique [14]. Pachouri and Yadav have carried out HPTLC analysis on a Bauhinia species to indicate the presence of various spots at different Rf values [15]. The above studies correlate with the results of present study. The $R_{f}$ values obtained will be helpful in the standardization of the drug. Thus, the results of the present study will provide information for the standardization of the medicinal plant, B. tomentosa.

\section{CONCLUSION}

It can be concluded that the results obtained from the HPTLC fingerprint analysis will be helpful in identification and standardization of $B$. tomentosa and can be used as a reference for the identification and quality control of the drug. As per literature survey, minimal work has been carried out in this variety. The results of the present study can be taken as a reference and the efficacy of the products can be done in the future which will validate the use of this plant for treating various ailments in the folklore system of medicine.

\section{AUTHORS CONTRIBUTION}

Dr. K. Vijayalakshmi designed the research work. R. Balabhaskar executed the current study and prepared the manuscript.

\section{CONFLICT OF INTEREST}

The authors declare no conflict of interest.

\section{REFERENCES}

1. Kumar AS, Reddy JR, Gupta VR. Preliminary phytochemical and standardization parameters of Ipomoea quamoclit Linn whole plant - An ethnomedicinally important plant. Int J Pharm Pharm Sci 2014;6:162-5.

2. Owolabi J, Omogbai EK, Obasuyi O. Antifungal and antibacterial activities of the ethanolic and aqueous extract of Kigelia Africana (Bignoniaceae) stem bark. Afr J Biotechnol 2007;6:882-5

3. Vaidya AD, Devasagayam TP. Current status of herbal drugs in India: An overview. J Clin Biochem Nutr 2007;41:1-1.

4. Calixto JB. Efficacy, safety, quality control, marketing and regulatory guidelines for herbal medicines (Phytotherapeutic agents). Braz J Med Biol Res 2000;33:179-89.

5. Paattanayak P, Behera M, Mohapatra P, Panda S. Standardization and evaluation of laxative activity of a poly herbal formulation. Pharm Lett 2011;3:276-86

6. Atmakuri LR, Dathi S. Current trends in herbal medicines. J Pharm Res 2010;3:109-13.

7. Dawane V, Fulekar MH. High-performance thin layer chromatography (HPTLC) fingerprinting pattern of mangrove Avicennia marina. Int $\mathrm{J}$ Pharm Pharm Sci 2017;9:65-72.

8. WHO. Quality Control Method for Medicinal Plant Material. Geneva: WHO 1998. p. 1-15.

9. Pattanaya P, Jena RK, Panda SK. HPTLC fingerprinting in the standardization of sulaharanyoga; An ayurvedic tablet formulation. Int J Pharm Sci Rev Res 2010;3:33-6.

10. Zhang YY, Sun SJ, Dai JY, Wang WY, Cao HJ, Wu JB, et al. Quality control method for herbal medicine-chemical fingerprint analysis. In: Shoyama Y, editor. Quality Control of Herbal Medicines and Related Areas. Rijeka: Intech; 2011. p. 171-94.

11. Shah CR, Suhagia BN, Shah NJ, Shah RR. Development and validation of a HPTLC method for the estimation of sumatriptan in tablet dosage forms. Indian J Pharm Sci 2008;70:831-4.

12. Mauji R, Abdin MZ, Khan MA, Prabhakar J. HPTLC Fingerprint Analysis: A Quality Control of Authentication of Herbal Phytochemicals. Verlag Berlin Heidelberg: Springer; 2011. p. 105.

13. Quriroga EN, Sampietro AR, Vattuone MA. Screening antifungal activities of selected medicinal plants. J Ethanopharmacol 2010;74:89-96.

14. Devaki K, Belah U, Gopalakrishnan VK. Finger print analysis of $P$. edulis and Bauhinia tomentosa using HPTLC technique. Asian J Pharm and Clin Res 2012;5:51-9.

15. Pachouri K, Yadav S. Physicochemical and phytochemical analysis of Bauhinia variegata modern analytical HPTLC fingerprinting. Int J Sci Eng Res 2015;6:2009-18. 